\title{
Identification of Self-(in)compatibility Alleles in Apricot by PCR and Sequence Analysis
}

\author{
Santiago Vilanova ${ }^{1,2}$, Carlos Romero', Gerardo Llácer, and María Luisa Badenes ${ }^{3}$ \\ Instituto Valenciano de Investigaciones Agrarias (IVIA), Moncada (Valencia) 46113, Spain \\ Lorenzo Burgos \\ Departamento de Mejora Genética y Patología Vegetal, CEBAS-CSIC, Murcia 164-30100, Spain
}

AdDitional InDEX words. breeding, introns, PCR, Prunus armeniaca, S-alleles, S-RNases

\begin{abstract}
This report shows the PCR-based identification of the eight known self-(in)compatibility alleles $\left(S_{1}\right.$ to $S_{7}$ and $S_{\mathrm{c}}$ ) of apricot (Prunus armeniaca $\mathbf{L}$.). Two sets of consensus primers, designed from $P$. armeniaca $S$-RNase genomic sequences and sweet cherry (P. avium L.) S-RNase-cDNAs, were used to amplify fragments containing the first and the second $S$-RNase intron, respectively. When the results obtained from the two PCRs were combined, all $S$-alleles could be distinguished. The identity of the amplified $S$-alleles was verified by sequencing the first intron and 135 base pairs (bp) of the second exon. The deduced amino acid sequences of these fragments showed the presence of the C1 and C2 Prunus L. $S$-RNase conserved regions. These results allowed us to confirm $S$-genotypes previously assigned by stylar ribonuclease analyses and to propose one self-(in)compatibility group (I) and one universal donor group (O) containing unique $S$-genotypes and self-compatible cultivars (SC). This PCR-based typing system also facilitates the identification of the $S_{\mathrm{c}}$-allele and might be a very useful tool for predicting self-compatibility in apricot breeding progenies.
\end{abstract}

Self-incompatibility (SI) is a common evolutionary strategy used by flowering plants to prevent self-fertilization and promote out-crossing (De Nettancourt, 1977). The Rosaceae, Solanaceae, and Scrophulariaceae present a SI gametophytic system based on S-RNases (Igic and Kohn, 2001). This type of SI is controlled by a highly multi-allelic locus, called the $S$-locus, and the feasibility of a cross is determined by the haploid genome of the pollen and the diploid genome of the pistil. Pollen tube growth is arrested if the same allele is present in both the pollen and the style (De Nettancourt, 1977).

Earlier works on Solanaceae species identified $S$-alleles encoding glycoproteins with RNase activity (Anderson et al., 1986; McClure et al., 1989). These $S$-RNases are involved in the inhibition of pollen tube growth, by $S$-allele-specific degradation of pollen RNA, in self-incompatibility reactions (Huang et al., 1994; McClure et al., 1990; Murfett et al., 1994). Nevertheless, the bases of the allelic interactions between $S$-RNases and the pollen $S$-allele products are not yet fully understood (Wang et al., 2003).

Most apricot cultivars grown in Europe, North America, South Africa, and Australia were considered self-compatible (Mehlenbacher et al., 1991). However, in the last two decades many widespread commercial cultivars have been described as self-incompatible (Burgos et al., 1993, 1997; Egea and Burgos, 1996; Glucina et al., 1988; Lamb and Stiles, 1983; Nyútjó et al., 1985). Self-compatibility is a desired trait in apricot breeding programs to ensure good crop production without using crosscompatible pollinators. Thus, self-incompatible apricot seedlings have to be detected and discarded. The assessment of pollen tube growth or fruit set after self-pollination, and even the analysis

Received for publication 1 Apr. 2005. Accepted for publication 12 May 2005. This research was supported by a grant from the Ministerio de Ciencia y Tecnología of Spain (AGL2001-1122-C02-02). All experiments described in this paper comply with the current laws of Spain.

'Both authors have contributed equally to this work.

2Present address: Departamento de Genética, IRTA Centre de Cabrils, Cabrils (Barcelona) 08348, Spain.

3To whom reprint requests should be addressed; e-mail: mbadenes@ivia.es of $S$-RNase proteins, require fully mature flowering trees and therefore are costly and time consuming in species with large juvenile periods (Alburquerque et al., 2002; Burgos et al., 1998). In Prunus, S-RNase genes involved in SI have been characterized in almond [P. dulcis (Mill.) D.A. Webb] (Ushijima et al., 1998), sweet cherry (Tao et al., 1999a), japanese apricot (P. mume Sieb. et Zucc.) (Yaegaki et al., 2001), sour cherry (P. cerasus L.) (Yamane et al., 2001), and apricot (Romero et al., 2004). The Prunus S-RNase coding region is interrupted by two introns that vary in size in an $S$-haplotype specific manner (Igic and Kohn, 2001; Ma and Oliveira, 2001; Romero et al., 2004; Tao et al., 1999b; Yamane et al., 2000). This feature has been very useful to speed up the $S$-alleles analysis. Indeed, PCR amplification based on conserved or specific primers designed from $S$-RNase DNA sequences has been used extensively for cultivar $S$-genotyping in almond (Channuntapipat et al., 2003; Tamura et al., 2000), sweet cherry (Sonneveld et al., 2001, 2003; Tao et al., 1999a; Wiersma et al., 2001; Wünsch and Hormaza, 2004; Yamane et al., 2000), and japanese apricot (Yaegaki et al., 2001).

The apricot $S$-locus structure has been analyzed in three different $S$-haplotypes $\left(S_{1}, S_{2}\right.$, and $S_{4}$ ) (Romero et al., 2004) allowing to develop specific PCR-primers to determine new self-incompatibility alleles. This work is aimed to identify by PCR the eight $S$-alleles (seven self-incompatible and one self-compatible) described to date in apricot through other methods (Alburquerque et al., 2002; Burgos et al., 1998). The application of the PCR-based identification would be a useful tool for $S$-genotyping in apricot breeding programs.

\section{Materials and Methods}

Plant material. Sixteen apricot accessions, kept at the collections of the Instituto Valenciano de Investigaciones Agrarias (IVIA) in Valencia (Spain) and at the Departamento de Mejora y Patología Vegetal (CEBAS-CSIC) in Murcia (Spain), were used in this study (Table 1). 'Goldrich', 'Sunglo', and 'Harcot' are North American cultivars. 'Currot', 'Palau', 'Ginesta', 'Canino', 'Colorao', and 'Moniquí' are Spanish cultivars and 'Beliana' is 
a French-Tunisian cultivar. In addition, seedlings from crosses among North American and Spanish cultivars ('Goldrich' $\mathrm{x}$ 'Currot', 'Sunglo' $x$ 'Palau', and 'Harcot' $x$ 'Ginesta') were included.

DNA extraction. Five grams of leaves of each accession were collected and stored at $-80{ }^{\circ} \mathrm{C}$ before DNA isolation. Genomic DNA was extracted from leaf samples following the method of Doyle and Doyle (1987). DNA quantification was performed by comparison with lambda DNA (Promega, Madison, Wis.).

$\boldsymbol{S}$ - $\boldsymbol{R} \boldsymbol{N}$ ASE ALlele identification by PCR anAlysis. Isolated genomic DNA from the cultivars and seedlings listed in Table 1 was used as a template for PCR. PCRs were performed in a final volume of $20 \mu \mathrm{L}$ containing $20 \mathrm{~mm}$ Tris- $\mathrm{HCl}(\mathrm{pH} 8.4), 50$ $\mathrm{mm} \mathrm{KCl,} 2.5 \mathrm{~mm} \mathrm{MgCl}_{2}, 0.2 \mathrm{~mm}$ of each dNTP, $0.25 \mu \mathrm{M}$ of each primer, $20 \mathrm{ng}$ of genomic DNA and $1 \mathrm{U}$ of Taq polymerase (Life Technologies, Rockville, Md.).

Two primers designed from conserved regions of $P$. armeniaca $S$-RNase genomic sequences, SRc-F (Romero et al. 2004) and SRc-R (this work), and one from P. avium S-RNase-cDNA sequences, Pru-T2 (Tao et al., 1999a), were used to amplify the first intron (Table 2; Fig. 1). The amplification was carried out using a temperature profile with an initial denaturing of $95^{\circ} \mathrm{C}$ for $3 \mathrm{~min} ; 35$ cycles of $95^{\circ} \mathrm{C}$ for $30 \mathrm{~s}, 54^{\circ} \mathrm{C}$ for $45 \mathrm{~s}$, and $72{ }^{\circ} \mathrm{C}$ for $1 \mathrm{~min} 15 \mathrm{~s}$; and a final extension of $72{ }^{\circ} \mathrm{C}$ for $10 \mathrm{~min}$ (Techne; Progene, Cambridge, U.K.).

To amplify the second intron, two sets of primers designed from $P$. avium $S$-RNase-cDNA sequences (Tao et al., 1999a) were used, Pru-C2/Pru-C4R and Pru-C2/Pru-C6R (Table 2; Fig. 1). PCRs were performed using the program previously described by Sonneveld et al. (2003) to amplify long PCR products. A fragment containing the two introns of the $S_{3}$-allele of 'Sunglo' $\left(S_{2} S_{3}\right)$ was PCR-amplified with the SRc-F/Pru-C6R primer combination, purified from the agarose gel, using the QIAquick Gel Extraction Kit (Qiagen, Hilden, Germany), and subsequently used as a template to obtain the second intron of the $S_{3}$-allele.

PCR products were electrophoresed in $0.8 \%$ or $2 \%(\mathrm{w} / \mathrm{v})$ agarose gels (second or first intron PCRs, respectively) using $1 \times$ TBE [ $89 \mathrm{~mm}$ Tris, $89 \mathrm{~mm}$ boric acid, and $2 \mathrm{~mm}$ EDTA $(\mathrm{pH}$ 8.0)) buffer, stained with ethidium bromide $\left.\left(0.8 \mu \mathrm{g} \cdot \mathrm{mL}^{-1}\right)\right]$ and visualized under UV light. Molecular sizes of amplified fragments were estimated using a 100-bp ladder (Life Technologies).

Sequencing of Genomic PCR Products. PCR products containing the first intron and a fragment $(\sim 135 \mathrm{bp})$ of the second exon of the $S_{3}, S_{5}, S_{6}, S_{7}$, and $S_{\mathrm{c}}-R N a$ se alleles were obtained from genomic DNA of the cultivars Sunglo $\left(S_{2} S_{3}\right)$, Colorao $\left(S_{5} S_{\mathrm{c}}\right)$, Moniquí $\left(S_{2} S_{6}\right)$, Beliana $\left(S_{7} S_{\mathrm{c}}\right)$, and Currot $\left(S_{\mathrm{c}} S_{\mathrm{c}}\right)$, respectively, using the primer combinations SRc-F/Pru-C2R and Pru-T2/PruC2R (only for $S_{6}$-allele) (Table 2; Fig. 1), and the PCR conditions described above to amplify the first intron. These fragments were extracted and purified from the agarose gels using the QIAquick GelExtraction Kit(Qiagen) and cloned into pGEM-Teasy plasmid vector (Promega) following the manufacturer's instructions. Plas-

Table 1. Apricot accessions evaluated in this study. Genotypes determined by stylar RNases analysis and/or cross-pollinations and confirmed by PCR, self-incompatibility groups proposed (I = self-incompatible, $\mathrm{O}=$ universal donors, $\mathrm{SC}=$ self-compatible) and references for accessions whose $S$-genotypes had been previously scored.

\begin{tabular}{|c|c|c|c|}
\hline Accessions & Genotype & Group & References \\
\hline Goldrich $^{z}$ & $S_{1} S_{2}$ & I & Egea and Burgos, 1996; Burgos et al., 1998 \\
\hline Sunglo & $S_{2} S_{3}$ & $\mathrm{O}$ & Burgos et al., 1998 \\
\hline Harcot & $S_{1} S_{4}$ & $\mathrm{O}$ & Burgos et al., 1998 \\
\hline Moniquí & $S_{2} S_{6}$ & $\mathrm{O}$ & Burgos et al., 1998 \\
\hline Canino & $S_{2} S_{\mathrm{c}}$ & $\mathrm{O}(\mathrm{SC})$ & Alburquerque et al., 2002 \\
\hline Colorao & $S_{5} S_{\mathrm{c}}$ & $\mathrm{O}(\mathrm{SC})$ & Burgos et al., 1998 \\
\hline Beliana & $S_{7} S_{\mathrm{c}}$ & $\mathrm{O}(\mathrm{SC})$ & Alburquerque et al., 2002 \\
\hline Currot & $S \mathrm{c} S_{\mathrm{c}}$ & $\mathrm{O}(\mathrm{SC})$ & Alburquerque et al., 2002 \\
\hline Palau & $S \mathrm{c} S_{\mathrm{c}}$ & $\mathrm{O}(\mathrm{SC})$ & J. Martínez, personal communication \\
\hline Ginesta & $S c S c$ & $\mathrm{O}(\mathrm{SC})$ & J. Martínez, personal communication \\
\hline Goldrich $\times$ Currot $(\mathrm{G} \times \mathrm{C}) 111$ & $S_{2} S_{\mathrm{c}}$ & $\mathrm{O}(\mathrm{SC})$ & \\
\hline Goldrich x Currot $(\mathrm{G} \times \mathrm{C}) 112$ & $S_{1} S_{\mathrm{c}}$ & $\mathrm{O}(\mathrm{SC})$ & \\
\hline Sunglo x Palau $(\mathrm{S} \times \mathrm{P}) 18$ & $S_{2} S_{\mathrm{c}}$ & $\mathrm{O}(\mathrm{SC})$ & \\
\hline Sunglo x Palau (S x P) 7 & $S_{3} S_{\mathrm{c}}$ & $\mathrm{O}(\mathrm{SC})$ & \\
\hline Harcot x Ginesta $(H \times G) 21$ & $S_{1} S_{\mathrm{c}}$ & $\mathrm{O}(\mathrm{SC})$ & \\
\hline Harcot x Ginesta $(H$ x G) 25 & $S_{4} S_{\mathrm{c}}$ & $\mathrm{O}(\mathrm{SC})$ & \\
\hline
\end{tabular}

$\bar{z}$ Cultivars Goldrich, Lambertin, and Hargrand conform the incompatibility group I, since all of them have the same $S$-genotype $S_{1} S_{2}$ determined by cross-pollinations (Egea and Burgos, 1996).

Table 2. Sequences of consensus primers used to amplify the first and the second intron of apricot $S$ RNases.

\begin{tabular}{lll}
\hline Primer & \multicolumn{1}{c}{ Sequence $\left(5^{\prime} \rightarrow 3^{\prime}\right)$} & \multicolumn{1}{c}{ Reference } \\
\hline SRc-F (forward) & CTC GCT TTC CTT GTT CTT GC & Romero et al., 2004 \\
SRc-R (reverse) & GGC CAT TGT TGC ACA AAT TG & this work \\
Pru-T2 (forward) & GTT CTT GCT TTT GCT TTC TTC & Tao et al., 1999a \\
Pru-C2 (forward) & CTT TGG CCA AGT AAT TAT TCA AAC C & Tao et al., 1999a \\
Pru-C2R (reverse) & GGT TTG AAT AAT TAC TTG GCC ATA G & Tao et al., 1999a \\
Pru-C4R (reverse) & GGA TGT GGT ACG ATT GAA GCG & Tao et al., 1999a \\
Pru-C6R (reverse) & CAT TGC CAC TTT CCA CGT C & Vilanova et al., 2003 \\
\hline
\end{tabular}




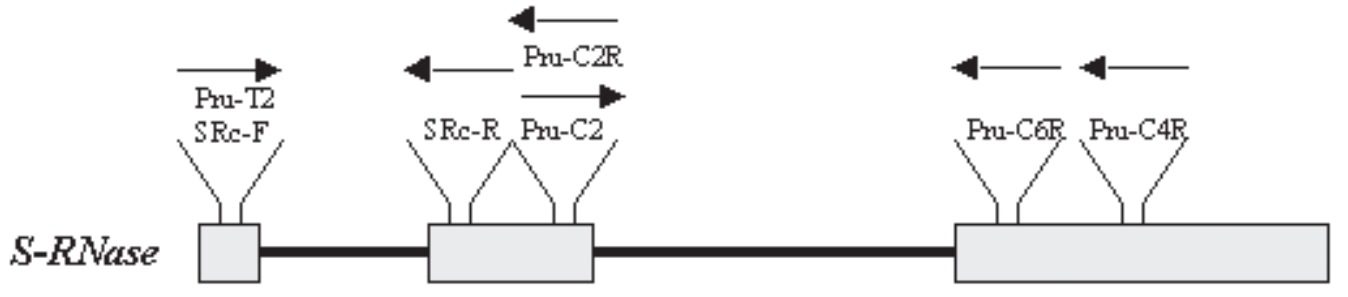

Fig. 1. Positions of the consensus primers used in this study in a Prunus S-RNase genomic DNA representation. Boxes and lines are exons and introns, respectively (not to scale).

A
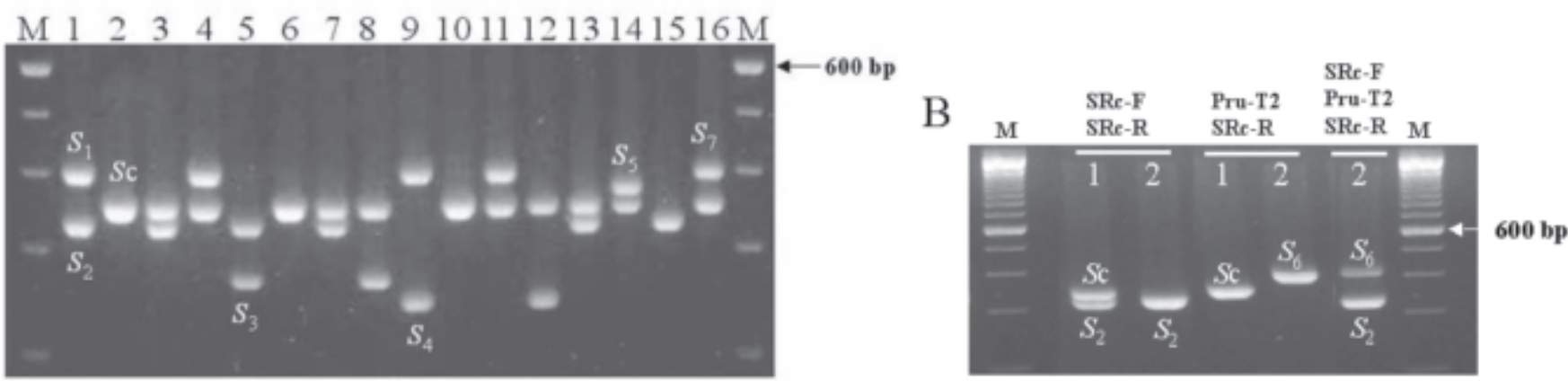

Fig. 2. PCR amplification of apricot genomic DNA with consensus primers for the first intron. (A) $S$-RNase allele fragments obtained with SRc-F/SRc-R primers. Samples are: (M) 100 bp DNA ladder, (1) 'Goldrich' $\left(S_{1} S_{2}\right),(2)$ 'Currot' $\left(S_{\mathrm{c}} S_{\mathrm{c}}\right),(3)$ 'G x C 111' $\left(S_{2} S_{\mathrm{c}}\right),(4)$ 'G x C 112' $\left(S_{1} S_{\mathrm{c}}\right),(5)$ 'Sunglo' $\left(S_{2} S_{3}\right),(6)$ 'Palau' $\left(S_{\mathrm{c}} S_{\mathrm{c}}\right)$, (7) 'S x P 18' $\left(S_{2} S_{\mathrm{c}}\right),(8)$ 'S x P 7' $\left(S_{3} S_{\mathrm{c}}\right),(9)$ 'Harcot' $\left(S_{1} S_{4}\right),(10)$ 'Ginesta' $\left(S_{\mathrm{c}} S_{\mathrm{c}}\right),(11)$ 'H x G 21' ( $\left.S_{1} S_{\mathrm{c}}\right),(12)$ 'H x G 25 ' $\left(S_{4} S_{\mathrm{c}}\right),(13)$ 'Canino' $\left(S_{2} S_{\mathrm{c}}\right),(14)$ 'C Colorao' $\left(S_{5} S_{c}\right),(15)$ 'Moniquí' $\left(S_{2} S_{6}\right)$ and (16) 'Beliana' $\left(S_{7} S_{\mathrm{c}}\right)$. (B) Identification of the $S_{6}$ allele with Pru-T2/SRc-R consensus primers for the first intron. Samples are: (1) 'Canino' $\left(S_{2} S_{\mathrm{c}}\right.$ ) as control and (2) 'Moniquí' $\left(S_{2} S_{6}\right)$ amplified with different primer combinations (SRc-F/SRc-R, Pru-T2/SRc-R, and Pru-T2 and SRc-F/SRc-R). M: 100 bp DNA ladder. Arrows indicate fragments of $600 \mathrm{bp}$.

mid DNA was isolated with the Rapid Plasmid Miniprep System (Marligen, Ijamsville, Md.). Three clones of each fragment were sequenced. Sequences were determined automatically using an ABI PRISM 377 DNA Sequencer (Applied Biosystems, Foster City, Calif.) and the BigDye Terminatorv1.1 Cycle Sequencing Kit (Applied Biosystems) following the manufacturer's instructions. Homology searches were performed using the BLASTX program (Altschul et al., 1990). Alignment of amino acid sequences was carried out with CLUSTALX (Thompson et al., 1997).

\section{Results}

PCR IDENTIFICATION OF APRICOT $\boldsymbol{S}$ - $R \boldsymbol{N}_{A S E}$ ALLELES. In the apricot accessions evaluated in this study (Table 1), fragments containing the first intron of the $S$-RNases were PCR-amplified using the SRc-F and SRc-R primers (Fig. 2). These fragments were assigned to particular $S$-alleles $\left(S_{1}\right.$ to $S_{7}$ and $S_{\mathrm{c}}$ ) by comparison with known $S$-genotypes, following the nomenclature established by Burgos et al. (1998). Furthermore, $S$-genotyping of seedlings from fully compatible crosses among North American and Spanish cultivars showed the segregation of the PCR products assigned to the $S$-alleles (Table 1; Figs. 2 and 3). Figure 2 A shows that the $\mathrm{SRc}-\mathrm{F} / \mathrm{SRc}-\mathrm{R}$ primer combination amplifies two $S$-RNase alleles in most of the cultivars, but only one in those homozygous for the self-compatibility $\left(S_{c}\right)$ allele and in 'Moniquí', whose $S_{6}$ allele was not amplified. Moreover, all $S$-alleles could be distinguished according to the size of the amplified fragments (from $\sim 250$ to $\sim 400 \mathrm{bp}$ ), except the $S_{1}$ and $S_{7}$-alleles that had the same fragment size (Table 3).

To obtain a fragment containing the first intron of the $S_{6}$-allele, the SRc-F primer was replaced by Pru-T2 (Table 3). This primer, previously designed from $P$. avium $S$-RNase-cDNA sequences
(Tao et al., 1999a), is significantly different in sequence from SRc-F even though it is located in a very close position. Figure $2 \mathrm{~B}$ shows that the $S_{6}$ allele of the cultivar Moniquí $\left(S_{2} S_{6}\right)$ can be detected with the Pru-T2/SRc-R combination but not with the SRc-F/SRc-R pair. However, for the $S_{2}$-allele the situation is the opposite, as it could not be detected with the Pru-T2/SRc-R primer combination (Fig. 2B). To amplify simultaneously fragments containing the first intron of the $S_{2}$ and $S_{6}$-alleles, the forward primers SRc-F and Pru-T2, and the reverse primer SRc-R, were used in the same PCR (Fig. 2B).

The second intron was amplified using a set of primers, PruC2/Pru-C4R, designed from $P$. avium $S$-RNase-cDNA sequences (Tao et al., 1999a). Two $S$-alleles were found in most of the accessions except in the $S_{\mathrm{c}}$ homozygous cultivars and in those containing the $S_{3}$-allele ['Sunglo' $\left(S_{2} S_{3}\right)$ and 'S x P 7' $\left(S_{3} S_{\mathrm{c}}\right)$ ] that was not amplified (Fig. 3A). With the primer pair Pru-C2/PruC6R, a fragment spanning the second intron of the $S_{3}$-allele failed to be amplified from 'Sunglo' $\left(S_{2} S_{3}\right)$ (Fig. 3B). However, $S_{2}$ and $S_{3}$-allele fragments containing both introns could be obtained using the SRc-F/Pru-C6R primer combination (Table3; Fig. 3C). Therefore, to facilitate the amplification of the $S_{3}$-allele second intron, nested PCR was performed using as a template the $S_{3}$-allele fragment containing the two introns instead of 'Sunglo' genomic DNA. Fig. 3C shows the $S_{3}$ PCR-amplified fragment containing the second intron.

Interestingly, the $S_{2}$-allele amplification product could not be observed in 'Moniquí' $\left(S_{2} S_{6}\right)$, even though it was amplified in the rest of the cultivars. The preferential amplification of the $S_{6}$ over the $S_{2}$-allele is due to differences in primer homologies; as when Pru-C4R is substituted with Pru-C6R, which is more homologous to the $S_{2}$ sequence, both alleles were amplified (Fig. $3 \mathrm{~B})$. In terms of the fragment size, all $S$-alleles were distinguished 
A

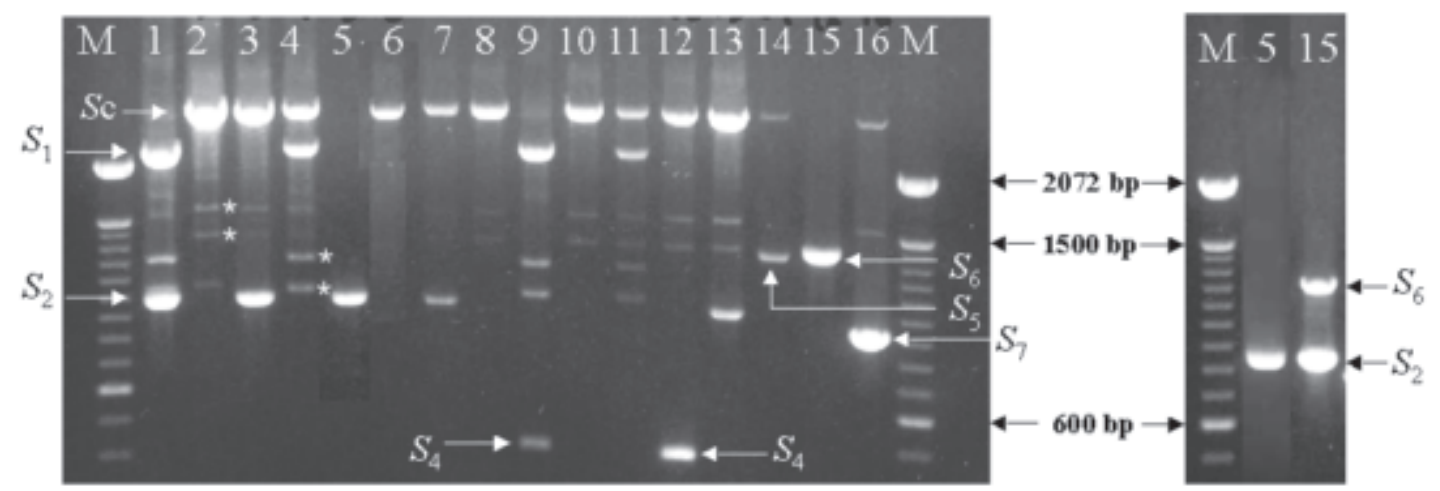

$\mathrm{C}$

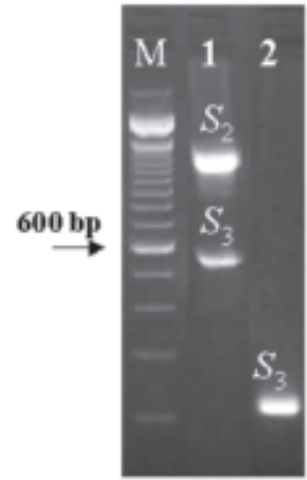

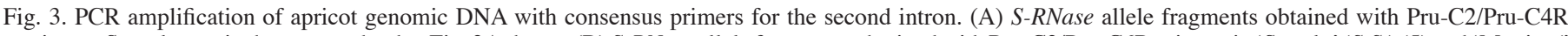

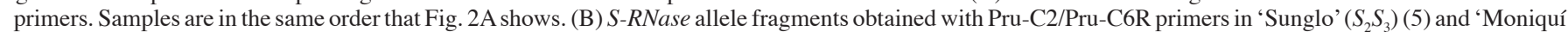

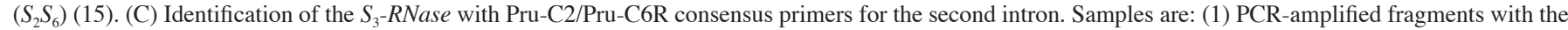

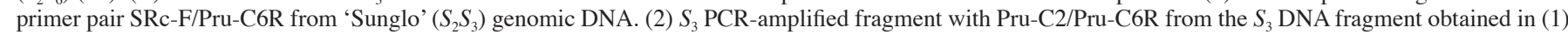
containing the two introns. M: 100-bp DNA ladder. Arrows indicate fragments of 600, 1500, and 2072 bp, and asterisks extra fragments.

Table 3. PCR fragment sizeobtained for each S-RNase allele with each primer combination.

\begin{tabular}{lcc}
\hline & \multicolumn{2}{c}{$\begin{array}{r}\text { DNA fragment length for each } \\
\text { primer combination (bp) }\end{array}$} \\
Alleles & SRc-F/SRc-R & Pru-C2/Pru-C4R $\mathbf{y}$ \\
S1 & 400 & 2260 \\
S2 & 327 & 990 \\
S3 & 267 & --- \\
S4 & 243 & 448 \\
S5 & 375 & $\sim 1400$ \\
S6 & --- & $\sim 1400$ \\
S7 & 400 & $\sim 900$ \\
S & 353 & $\sim 2800$ \\
& Pru-T2/SRc-R & SRc-F/Pru-C6R \\
S6 & 407 & --- \\
S3 & --- & $\sim 580$ \\
\hline
\end{tabular}

${ }^{2}$ PCR fragments containing the first intron of the $S$-RNase alleles.

yPCR fragments containing the second intron of the $S$ RNase alleles.

xPCR fragments containing both introns of the $S$-RNase alleles.

(fragments from $\approx 450$ to more than $\approx 2500 \mathrm{bp}$ ), except $S_{5}$ and $S_{6}$, with very similar sizes (Table 3 ). Two extra fragments or artifacts of different sizes were detected in every sample containing $S_{1}$ or $S_{\mathrm{c}}$-alleles (Fig. 3A).

Sequence analysis of the APRicot $\boldsymbol{S}$ - $R \boldsymbol{N}$ ASE Alleles. PCR amplification fragments spanning the first intron, assigned to $S_{3}, S_{5}, S_{6}, S_{7}$, and $S_{\mathrm{c}}$-alleles, were sequenced and compared with GenBank accessions. All of them showed homology with other Prunus S-RNases already identified (data not shown). The alignment of their deduced amino acid sequences showed the presence of the $\mathrm{C} 1$ and $\mathrm{C} 2$ Prunus $S$-RNase conserved domains along with the hypervariable region HV1 located between them (Fig. 4).

These results, and the previously reported genomic structures of apricot $S_{1}, S_{2}$, and $S_{4}$-alleles (Romero et al., 2004), allowed us to deduce the basic structure of the $S_{3}, S_{5}, S_{6}, S_{7}$, and $S_{\mathrm{c}}-$ RNase alleles, although full-length sequences are not yet available. Figure 5 shows the structure of the $P$. armeniaca $S_{1}$ to $S_{7}$ and $S_{c}-R N a s e$ alleles as well as the exact sizes of the $S_{1}, S_{2}$, and $S_{4}$-allele exons and introns (Romero et al., 2004). For the rest of the $S$-RNase al-

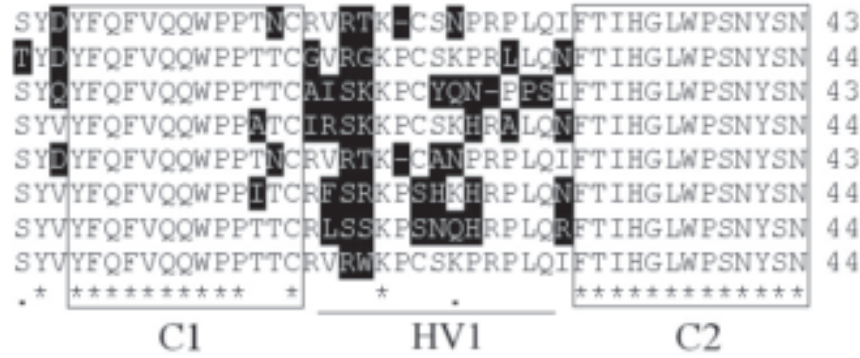

ig. 4. Alignment of the deduced amino acid sequences of S-RNase second exon fragments from apricot Par. Par- $S_{1}, S_{2}$, and $S_{4}$ sequences were previously reported by Romero et al. (2004) re highlighted in black boxes. Conserved regions $(\mathrm{C} 1$ and $\mathrm{C} 2)$ are boxed and the hypervariable region (HV1) underlined. 
leles identified, exact or approximate sizes of the first and second intron, respectively, are also indicated. These data show that size variability in the first intron (from 151 to $329 \mathrm{bp}$ ) is clearly lower than in the second one (from $\sim 110$ to more than $2500 \mathrm{bp}$ ).

\section{Discussion}

IDENTIFICATION OF SELF-(IN)COMPATIBILITY ALLELES IN APRICOT. To date, the detection of the apricot $S$-alleles had been performed via stylar ribonuclease analysis (Alburquerque et al., 2002; Burgos et al., 1998). In other Prunus species, identification of $S$-alleles has been already achieved by the more practical DNA-based methods (Tao et al., 1999a; Ushijima et al., 1998). In fact, the highly divergent size of the introns in Prunus $S$-RNases provides a convenient basis for distinguishing $S$-alleles by PCR amplification. Taking advantage of this feature, Wiersma et al. (2001) identified new $S$-alleles in sweet cherry by PCR using degenerate primers to amplify fragments containing both introns of the $S$ RNase separately. However, attempts to amplify the first intron were not so satisfactory in apricot, when performed with these and other primers previously reported in almond (Ushijima et al., 1998) and sweet cherry (Tao et al., 1999a) (data not shown). The recent identification and cloning of the first three apricot $S$-RNase alleles (Romero et al., 2004) allowed us to design consensus primers (SRc-F/SRc-R) for amplification of the first intron. These new primers seem to be well conserved in most apricot $S$-alleles and produced better results than those developed from cherry. Nevertheless, primers designed by Tao et al. (1999a) to amplify the second intron (Pru-C2/Pru-C4R) seem to be better conserved among all the Prunus species analyzed, and therefore they could be also used in apricot.

PCRs with the SRc-F/SRc-R primer combination identified most $S$-RNase alleles. However, $S_{1}$ and $S_{7}$-RNase alleles, whose first intron shows exactly the same size (308 bp), could not be distinguished. In addition, to amplify the $S_{6}$-allele SRc-F had to be replaced by Pru-T2 (Tao et al., 1999a). These results indicated that PCR amplifications of the second intron were necessary to determine $S$-genotypes unambiguously. The Pru-C2/Pru-C4R primer combination was also useful to distinguish most $S$-alleles with the exception of $S_{5}$ and $S_{6}$, similar in size, and $S_{3}$, that did not amplify directly from genomic DNA. When the results were combined, apricot $S_{1}$ to $S_{7}$ and $S_{\mathrm{c}}$-alleles were identified unequivocally. However, the use of alternative approaches based on $S$-RNase allele specific primers or restriction analysis might be necessary for the identification of new $S$-alleles in the future.

Interestingly, in zymograms of stylar protein extracts from the apricot cultivars Priana and Beliana, RNases associated with $S_{7}$ and $S_{\mathrm{c}}$ alleles migrate to the same position (Alburquerque et al., 2002). However, results of this report indicate that they are encoded by two different $S$-alleles, since they produce distinct band patterns after PCR amplification with the two primer sets used, and show different sequences in the $S$-RNase second exon fragments analyzed (Fig. 4).

PCR-based $S$-genotyping has confirmed the data previously obtained by means of controlled pollinations and stylar RNase analyses (Alburquerque et al., 2002; Burgos et al., 1998; Egea and Burgos, 1996). Following the designation established for sweet cherry, we propose to group apricot cultivars in one self(in)compatibility group (I) and one universal donor group (O) containing unique $S$-genotypes and self-compatible cultivars (SC). The knowledge on the $S$-genotype of cultivars has been used in breeding programs to design controlled crosses that produce only self-compatible seedlings (Alburquerque et al., 2002). However, the evaluation of self-compatibility is necessary when the progeny of a given cross segregates for this trait. It is important to emphasize that all genotypes containing the $S_{\mathrm{c}}$-allele are self-compatible, a phenotype recently associated with the loss of pollen- $S$ function in $P$. avium and $P$. mume (Ushijima et al., 2004). Therefore, the simple and reliable PCR identification of the $S_{\text {c-allele would be }}$ of great help in the selection process of breeding programs.

APricot $\boldsymbol{S}$ - $R \boldsymbol{N}$ Ase Alleles genOMic DNAstructure. Genomic structure of the apricot $S_{3}, S_{5}, S_{6}, S_{7}$, and $S_{\mathrm{c}}$-RNase alleles had not been previously described. In this work, the DNA lengths of PCR-amplified fragments containing the first intron were exactly determined. In addition, their deduced amino acid sequences were aligned and the homology of the hypervariable region HV1 analyzed (Kheyr-Pour et al., 1990). Taking together these data allowed us to distinguish all $S$-alleles. Sequencing and/or test-crossing are advisable to confirm PCR-identification of new $S$-alleles. In fact, slight differences at the intron level were found in almond between $S b$ and $S 1$-alleles which exons showed $100 \%$ homology (Channuntapipat et al., 2001; Ma and Oliveira, 2001).

Just as was previously observed in $P$. avium (Sonneveld et al., 2003; Wiersma et al., 2001; Wünsch and Hormaza, 2004), $S$-RNase intron size variability in apricot is lower for intron 1 than for intron 2 . These differences in intron size variability might be correlated with their positions within the $S$-RNase genomic sequence. Tamura et al. (2000) suggested a relationship between the high variability in size of the second intron and its position within the hypervariable region, presumably responsible for the self-recognition specificity (Ishimizu et al., 1998; Matton et al., 1997). In agreement with this, the first intron is located within the signal peptide and the mature protein (Sonneveld et al., 2003) in a relatively conserved region and therefore does not seem to be involved in the recognition mechanism.

PCR amplifications with primers spanning the second intron were difficult as long PCR conditions described by Sonneveld et al. (2003) were critical to amplify these fragments. These difficulties seem to be related not only to the long length of the second intron in certain $S$-RNase alleles, but also to the presence of repetitive sequences and microsatellites within the introns (Romero et al., 2004). Sonneveld et al. (2003) observed extra fragments or artifacts when amplifying the second intron of the sweet cherry $S_{5}$ and $S_{13}$-alleles. These authors suggested that the artifacts are related to the secondary structure of the DNA, which promotes polymerase jumping during PCR amplification. Moreover, they pointed out that the amplification of the artifacts can also be associated with the presence of a microsatellite (TA $)_{20}$ within the intron. Similarly, two reproducible extra fragments have also been detected in all the apricot cultivars containing the $S_{1}$ or the $S_{\mathrm{c}}$-allele when amplifying the second intron. In addition, two long SSRs [(TA) and (TA $)_{14}$ ] have been found within the second intron of the $S_{1}$

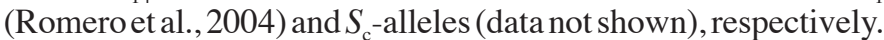
Interestingly, the sizes of the extra fragments observed suggest that a single strand amplification occurred between the Pru-C2 or Pru-C4R primers and the (TA) microsatellites due to the DNA polymerase inability of continuing on beyond. This result might explain why similar fragments could not be cloned or sequenced by Sonneveld et al. (2003).

In conclusion, $S$-genotyping through PCR can be a very useful method in the ongoing apricot breeding programs. However, the identification of $S$-alleles from new cultivars should be approached with caution. Collection of cross-pollination and sequencing data would be necessary to confirm new $S$-alleles. 


\section{Literature Cited}

Alburquerque, N., J. Egea, O. Pérez-Tornero, and L. Burgos. 2002. Genotyping apricot cultivars for self-(in)compatibility by means of RNases associated with $S$ alleles. Plant Breeding 121:343-347.

Altschul, S.F., W. Gish, W. Miller, E.W. Myers, and D.J. Lipman. 1990. Basic local alignment search tool. J. Mol. Biol. 215:403-410.

Anderson, M.A., E.C. Cornish, S-L. Mau, E.G. Williams, R. Hoggart, A. Atkinson, I. Bonig, B. Grego, R. Simpson, P.J. Roche, J.D. Haley, J.D. Penschow, H.D. Niall, G.W. Tregear, J.P. Coghlan, R.J. Crawford, and A.E. Clarke. 1986. Cloning of cDNA for a stylar glycoprotein associated with expression of self-incompatibility in Nicotiana alata. Nature 321:38-44.

Burgos, L., T. Berenguer, and J. Egea. 1993. Self- and cross-compatibility among apricot cultivars. HortScience 28:148-150.

Burgos, L., J. Egea, R. Guerriero, R. Viti, P. Monteleone, and J.M. Audergon. 1997. The self-compatibility trait of the main apricot cultivars and new selections from breeding programmes. J. Hort. Sci. 72:147-154.

Burgos, L., O. Pérez-Tornero, J. Ballester, and E. Olmos. 1998. Detection and inheritance of stylar ribonucleases associated with incompatibility alleles in apricot. Sexual Plant Reproduction 11:153-158.

Channuntapipat, C., M. Sedgley, and G.G. Collins. 2001. Sequences of the cDNAs and genomic DNAs encoding the $S 1, S 7, S 8$, and $S$ f alleles from almond, Prunus dulcis. Theor. Appl. Genet. 103:1115-1122.

Channuntapipat, C., M. Wirthensohn, S.A. Ramesh, I. Batlle, P. Arús, M. Sedgley, and G.G. Collins. 2003. Identification of incompatibility genotypes in almond (Prunus dulcis Mill.) using specific primers based on the introns of the $S$-alleles. Plant Breeding 122:164-168.

De Nettancourt, D. 1977. Incompatibility in angiosperms. Monographs on theoretical and applied genetics, 3. Springer-Verlag, New York.

Doyle, J.J. and J.L. Doyle. 1987. A rapid isolation procedure for small quantities of fresh leaf tissue. Phytochem. Bul. 19:11-15.

Egea, J. and L. Burgos. 1996. Detecting cross-incompatibility of three North American apricot cultivars and establishing the first incompatibility group in apricot. J. Amer. Soc. Hort. Sci. 121:1002-1005.

Glucina, P.G., R.W. Bristol, and I.K. Lewis. 1988. Cluthagold: A promising new late season apricot. Orchardist N.Z. 61:37.

Huang, S., H.S. Lee, B. Karunanandaa, and T.H. Kao. 1994. Ribonuclease activity of Petunia inflata $\mathrm{S}$ proteins is essential for rejection of self-pollen. Plant Cell 6:1021-1028.

Igic, B. and J.R. Kohn. 2001. Evolutionary relationships among self-incompatibility RNases. Proc. Natl. Acad. Sci. USA 98:1316713171.

Ishimizu, T., T. Endo, Y. Yamaguchi-Kabata, K.T. Nakamura, F. Sakiyama, and S. Norioka. 1998. Identification of regions in which positive selection may operate in S-RNase of Rosaceae: Implication for S-allele-specific recognition sites in S-RNase. FEBS Lett. 440:337-342.

Kheyr-Pour, A., S.B. Bintrim, T.R. Ioerger, R. Remy, S.A. Hammond, and T.H. Kao. 1990. Sequence diversity of pistil S-proteins associated with gametophytic self-incompatibility in Nicotiana alata. Sexual Plant Reproduction 3:88-97.

Lamb, R.C. and W.C. Stiles. 1983. Apricots for New York state. New York Food and Life Sci. Bul. 100:1-4.

Ma, R.C. and M.M. Oliveira. 2001. Molecular cloning of the self-incompatibility genes $S 1$ and $S 3$ from almond (Prunus dulcis cv. Ferragnès). Sexual Plant Reproduction 14:163-167.

Matton, D.P., O. Maes, G. Laublin, Q. Xike, C. Bertrand, D. Morse, and M. Cappadocia. 1997. Hypervariable domains of self-incompatibility RNases mediate allele specific pollen recognition. Plant Cell 9:1757-1766.

McClure, B.A., J.E. Gray, M.A. Anderson, and A.E. Clarke. 1990. Self-incompatibility in Nicotiana alata involves degradation of pollen rRNA. Nature 347:757-760.

McClure, B.A., V. Haring, P.R. Ebert, M.A. Anderson, R.J. Simpson, F. Sakiyama, and A.E. Clarke. 1989. Style self-incompatibility gene products of Nicotiana alata are ribonucleases. Nature 342:955-957.

Mehlenbacher, S.A., V. Cociu, and L.F. Hough. 1991. Apricots (Prunus), p. 65-107. In: J.N. Moore and J.R. Ballington (eds.). Genetic resources of temperate fruit and nut crops. Intl. Soc. Hort. Sci., Wageningen, The Netherlands.

Murfett, J., T.L. Atherton, B. Mou, C.S. Gasser, and B.A. McClure. 1994. S-RNase expressed in transgenic Nicotiana causes S-allele-specific pollen rejection. Nature 367:563-566.

Nyútjó, F., S. Brózik Jr., S. Brózik, and J. Nyéki. 1985. Fruit set in apricot varieties. Acta Agronomica Academiae Scientarum Hungaricae 34 (1-2):65-72.

Romero, C., S. Vilanova, L. Burgos, J. Martínez-Calvo, M. Vicente, G. Llácer, and M.L. Badenes. 2004. Analysis of the $S$-locus structure in Prunus armeniaca L. Identification of $S$-haplotype $S$-RNase and $F$-box genes. Plant Mol. Biol. 56:145-157.

Sonneveld, T., T.P. Robbins, R. Boskovic, and K.R. Tobutt. 2001. Cloning of six cherry self-incompatibility alleles and development of allelespecific PCR detection. Theor. Appl. Genet. 102:1046-1055.

Sonneveld, T., K.R. Tobutt, and T.P. Robbins. 2003. Allele-specific PCR detection of sweet cherry self-incompatibility (S) alleles S1 to S16 using consensus and allele-specific primers. Theor. Appl. Genet. 107(6):1059-1070.

Tamura, M., K. Ushijima, H. Sassa, H. Hirano, R. Tao, T.M. Gradziel, and A.M. Dandekar. 2000. Identification of self-incompatibility genotypes of almond by allele-specific PCR analysis. Theor. Appl. Genet. 101:344-349.

Tao, R., H. Yamane, and A. Sugiura. 1999a. Molecular typing of S-alleles through identification, characterization and cDNAcloning for S-RNAses in sweet cherry. J. Amer. Soc. Hort. Sci. 124(3):224-233.

Tao, R., H. Yamane, and H. Akira. 1999b. Cloning and genomic DNA sequences encoding S1-, S3-, S4-, and S6-RNases (Accessions Nos. $\mathrm{AB} 031815, \mathrm{AB} 031816, \mathrm{AB} 031817, \mathrm{AB} 031818)$ from sweet cherry (Prunus avium L.). Plant Physiol. 121:1057.

Thompson, J.D., T.J. Gibson, F. Plewniak, F. Jeanmougin, and D.G. Higgins. 1997. The ClustalX windows interface: Flexible strategies for multiple sequence alignment aided by quality analysis tools. Nucleic Acids Res. 25:4876-4882.

Ushijima, K., H. Sassa, R. Tao, H. Yamane, A.M. Dandekar, T.M. Gradziel, and H. Hirano. 1998. Cloning and characterization of cDNAs encoding S-RNases from almond (Prunus dulcis): Primary structural features and sequence diversity of the S-RNases in Rosaceae. Mol. Gen. Genet. 260:261-268.

Ushijima, K., H. Yamane, A. Watari, E. Kakehi, K. Ikeda, N.R. Hauck, A. Iezzoni, and R. Tao. 2004. The $S$ haplotype-specific F-box protein gene, $S F B$, is defective in self-compatible haplotypes of Prunus avium and P. mume. Plant J. 39:573-586.

Vilanova, S., C. Romero, D. Abernathy,A.G. Abbott, L. Burgos, G. Llacer, and M.L. Badenes. 2003. Construction and application of a bacterial artificial chromosome (BAC) library of Prunus armeniaca L. for the identification of clones linked to the self-incompatibility locus. Mol. Genet. Genomics. 269:685-691.

Wang, Y., X. Wang, A.L. Skirpan, and T.H. Kao. 2003. S-RNase-mediated self-incompatibility. J. Expt. Bot. 54:115-122.

Wiersma, P.A., Z. Wu, L. Zhou, C. Hampson, and F. Kappel. 2001. Identification of new self-incompatibility alleles in sweet cherry (Prunus avium L.) and clarification of incompatibility groups by PCR and sequencing analysis. Theor. Appl. Genet. 102:700-708.

Wünsch, A. and J. Hormaza. 2004. Cloning and characterization of genomic DNA sequences of four self-incompatibility alleles in sweet cherry (Prunus avium L.). Theor. Appl. Genet. 108:299-305.

Yaegaki, H., T. Shimada, T. Moriguchi, H. Hayama, T. Haji, M. Yamaguchi. 2001. Molecular characterization of S-RNase genes and S-genotypes in the japanese apricot (Prunus mume Sieb. et Zucc.). Sexual Plant Reproduction 13:251-257.

Yamane, H., R. Tao, H. Murayama, and A. Sugiura. 2000. Determining the S-genotypes of several sweet cherry cultivars based on PCR-RFLP analysis. J. Hort. Sci. Biotechnol. 75:562-567.

Yamane, H., R. Tao, A. Sugiura, N.R. Hauck, and A.F. Iezzoni. 2001. Identification and characterization of S-RNases in tetraploid sour cherry (Prunus cerasus). J. Amer. Soc. Hort. Sci. 126:661-667. 